guts. In the animals' brains, researchers found fewer neurons containing oxytocin, a hormone that is related to social behaviour. Electrical signalling in the ventral tegmental area, a brain region that processes rewarding stimuli, did not strengthen as it normally does following new social interactions.

The team identified a gut bacterium, Lactobacillus reuteri, that reversed these abnormalities when it was given to the high-fat-diet offspring.

Cell 165, 1762-1775 (2016)

MEDICAL DEVICES

\section{Insect-eye camera peers inside gut}

Mini cameras at the end of a probe that are designed to 'see' like an insect's compound eye could eventually be used in medical endoscopes.

Ömer Cogal and Yusuf Leblebici at the Swiss Federal Institute of Technology in Lausanne built a domeshaped device measuring 10 millimetres wide with 24 tiny cameras covering its surface (pictured). In between the cameras are small, lightemitting fibre-optic cables. The cameras are placed in a way that provides a $180^{\circ} \times 180^{\circ}$ or $360^{\circ} \times 90^{\circ}$ panoramic field of view. The researchers found that the resolution of the system was 1,000 times higher than other insect-eye-inspired devices of a similar size.

When tested inside a tube mimicking a human colon, the device could reveal areas that are normally missed by conventional endoscopes. IEEE Trans. Biomed. Circuits Syst. http://doi.org/bj3q (2016)

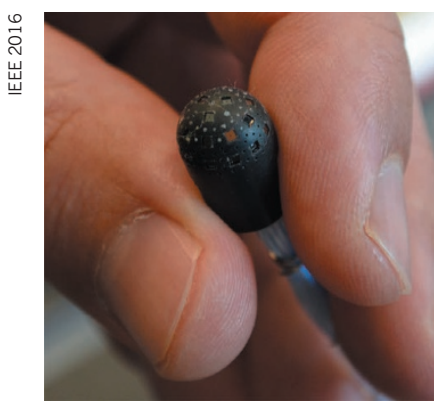

THERAPEUTICS

\section{Antibody double} trouble for HIV

Genetically engineered human antibodies that bind to two targets on HIV could one day be used to treat and prevent the disease.

'Broadly neutralizing' antibodies can block various HIV strains, but the virus can overcome them by changing the viral protein that the antibodies recognize. To combat this viral escape, a team led by Jeffrey Ravetch at the Rockefeller University in New York City developed HIV antibodies that can recognize two different spots on the envelope protein that adorns the virus. One of these bispecific antibodies lowered viral levels in HIV-infected mice by more than tenfold in comparison with broadly neutralizing antibodies.

An independent team led by David Ho, also at the Rockefeller University, created bispecific antibodies that recognize both the HIV envelope protein and human proteins that HIV uses to infect immune cells. The most potent of these antibodies protected mice from becoming infected with HIV and decreased viral levels in those already infected.

Cell 165, 1609-1620;

1621-1631 (2016)

\section{ORGANIC CHEMISTRY}

\section{Plastic waste turned into fuel}

Plastic from bottles and bags can be degraded into liquid fuels and waxes using available catalysts.

Polyethylene is the world's most common plastic, but is difficult to break down, typically requiring temperatures higher than $400^{\circ} \mathrm{C}$. A team led by Zheng Huang at the Shanghai Institute of Organic Chemistry in China and Zhibin Guan at the University of California, Irvine, used low-cost and widely available reagents

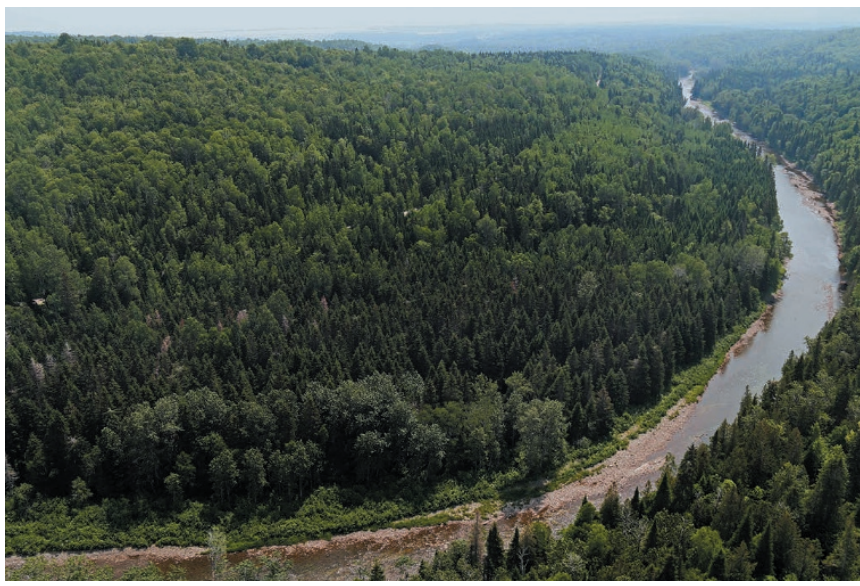

called light alkanes, along with key catalysts, to convert polyethylene into oils and waxes. The team broke down various forms of the plastic into oil at $175^{\circ} \mathrm{C}$ within 4 days, at efficiencies ranging from $51 \%$ to $86 \%$.

The team also used their process to convert $57-72 \%$ of everyday plastic waste such as bottles and bags into oils. Sci. Adv. 2, e1501591 (2016)

\section{ECOLOGY}

\section{A climate refuge for trees}

Forests in northeastern North America (pictured) could thrive in a warmer climate.

How trees will react to a warmer environment is unclear; low average temperatures hamper their growth but higher temperatures can limit water availability. Loic D’Orangeville of the University of Quebec at Montreal in Canada and his colleagues used tree-ring data from more than 16,000 stands of black spruce (Picea mariana) across Quebec to track growth between 1960 and 2004. They found that north of a latitude of $49^{\circ} \mathrm{N}$, increased temperature had positive effects on tree growth, despite the lower availability of water. Below that latitude, however, only an increase in water availability boosted tree growth.

Although boreal forests in central and western North America might be negatively affected by climate change, northeastern areas could act as a refuge for certain trees, the authors suggest.

Science 352, 1452-1455 (2016)

\section{NEUROBIOLOGY}

\section{Mitochondria make nerves grow}

Enhancing the mobility of energy-producing structures called mitochondria in injured neurons helps these cells to regenerate in mice.

After an injury, some young neurons can regrow their long signalling arms known as axons, but mature cells cannot. Zu-Hang Sheng of the National Institutes of Health in Bethesda, Maryland, and his colleagues knocked out a gene called Snph in cultured mouse neurons. The gene encodes a protein, syntaphilin, that anchors mitochondria inside cells. The team found that $69 \%$ of young neurons lacking the gene began to form growing tips, compared with only $44 \%$ that had the gene. Similar effects were seen in adult mice, and injured mature neurons showed an increasing ability to regenerate with declining levels of syntaphilin.

Replenishing the energy supply in damaged axons by boosting the transport of mitochondria could be one way to treat nerve injuries, the authors suggest.

J. Cell Biol. http://doi.org/bj3n (2016)

\section{DNATURE.COM}

For the latest research published by Naturevisit:

www.nature.com/latestresearch 